\title{
SOME CURIOUS FINDINGS HAIR FOLLICLES BIOELECTROMAG- NETIC RADIATION EXPRESSED AS LIGHT DISPLACING MATTER IN ITS PATH AND THE CONTRALATERAL EMISSION OF MAGNETIC FIELDS FOUND IN THE HAIR SHAFT
}

\author{
Abraham A. Embi ${ }^{1}$ (D) \\ ${ }^{1}$ BS MBA,13442 SW 102 Lane Miami, 33186, Florida
}
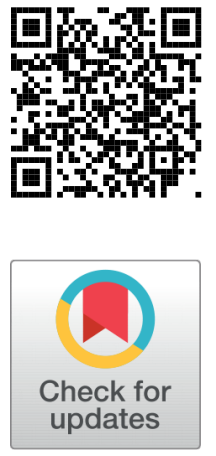

Received 4 July 2021

Accepted 17 July 2021

Published 31 July 2021

Corresponding Author

Abraham A. Embi, embi21@att.net

DOI $10.29121 /$

granthaalayah.v9.i7.2021.4114

Funding: This research received no specific grant from any funding agency in the public, commercial, or not-for-profit sectors.

Copyright: (C) 2021 The Author(s). This is an open access article distributed under the terms of the Creative Commons Attribution License, which permits unrestricted use, distribution, and reproduction in any medium, provided the original author and source are credited.

\section{ABSTRACT}

BACKGROUND: A mini-review of prior experiments by this author and others are herein presented where bioelectromagnetic fields expressed as light are shown displacing matter of ferric cyanide chemical compounds. A seminal paper published in 1980, is also included where human hair follicles had been documented as emitting magnetic fields when applying pressure on the human scalp.

METHODS: In physics the term light refers to electromagnetic radiation, which includes visible light, which has also been described as exerting physical pressure on matter in its path; this could be explained by the "particle nature of light". To date light rays' emission experiments has been done mainly on nonliving matter. This manuscript will show in vitro results where biological tissue (hair follicles) is shown emitting electromagnetic radiation in a light form and displacing particles in its path. Additionally, the hair shaft one-sided biomagnetism is shown.

RESULTS: Findings are presented where light rays or flashes emitted by hair follicles are documented to exert pressure in matter in its path causing displacement; and in one case a flash of light seen as a primary factor in totally reversing turmoil caused by a piezoelectric or pressure induced maneuver. As an incidental finding: The hair shaft is also found to express one-sided magnetic fields similar to inanimate magnets inhibiting human blood issue fibrin formation (clot formation).

CONCLUSIONS: Presented is a mini-review of biological tissue previously found to emit magnetic fields, now also expressed as light. The light is displayed shown as a "flash" or a "stream", in both instances displacing matter in its path. The light flash also appears to be a primary factor in bringing equilibrium into the piezoelectric disturbed bioelectromagnetic field. Question arise: What is/are the biological/molecular consequences of living tissue under stress emitting light energy? Why is the hair shaft bioelectromamagnetic field shown in a contralateral fashion, this when the hair follicle is not? Further research is 
recommended.

\section{DEFINITIONS OF TERMS}

- Particle Nature of Light: Light exerts physical pressure on objects in its path, a phenomenon which can be deduced by Maxwell's equations, but can be more easily explained by the particle nature of light: photons strike and transfer their momentum. (Wikipedia).

- Electromagnetic Radiation: "a kind of radiation including visible light, radio waves, gamma rays, and X-rays, in which electric and magnetic fields vary simultaneously". (From Oxford Dictionary)

- Biolectromagnetism is interdisciplinary because involves "the association of life and sciences with the physical and engineering sciences"

- Mechano-Electrical Transduction: The conversion of force into electricity.

Keywords: Biolectromagnetism, Hair Follicles, Rodent Whiskers, Light Matter Interaction, Duality of Light, Migraine Headaches, Piezoelectric Effect, Hair Shaft One-Sided Magnetic Fields

\section{INTRODUCTION}

\section{Living Biological Tissue Light Rays Displacing Matter}

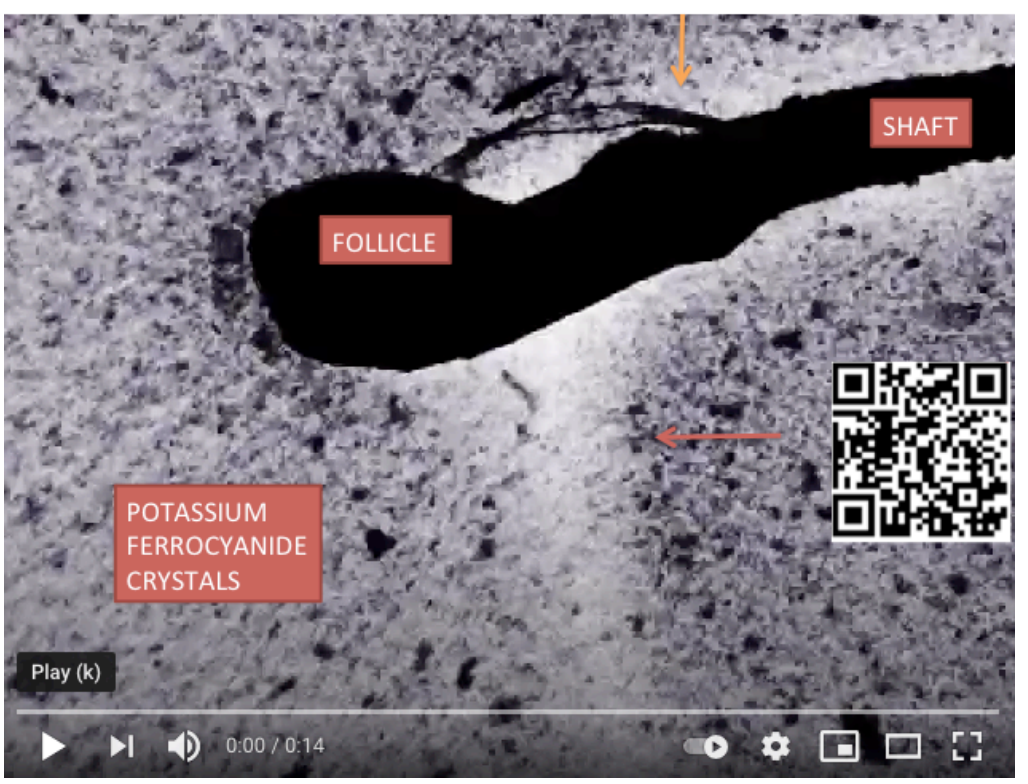

Figure 1 Control rodent follicle sandwiched between two glass slides showing particles moving around follicle- Notice light emanating from follicle. Compare with human follicle in separate experiment. Top Orange Arrow: Undisturbed filament. Bottom Red Arrow: Light Ray stopping crystals from crossing. For details link to: https://www.youtube.com/watch?v=EiYKpN7-PpY Or Scan QR Code in right side of image. 


\section{UNPUBLISHED VIDEO SHOWING RODENT FACIAL WHISKER EMITTING LIGHT AND DISPLACING MATTER}

The main purpose of this manuscript is threefold, the first is to introduce an unpublished image from a previously published experiment (1) where applied finger pressure was exerted on a rodent whisker immersed in liquid Potassium Ferrocyanide and placed between two glass slides. In this case, shown is the emission of an unexpected intense light flash physically displacing matter (whiskers Filaments) (Figures 1 and 2 plus video). The second purpose is to group similar images where light rays are also shown displacing matter (Exhibits 1,2,3,4,5). The third, the prevalence of a one-sided hair shaft magnetic field (contralateral side) (6) Figure 3 ).

FINGER PRESSURE APPLIED TO SANDWICHED WHISKER IMMERSED IN PRUSSIAN BLUE STAIN THE PIEZOELECTRIC EFFECT AND LIGHT DISPLACING HAIR FILAMENT NOW SEEN UNDER FOLLICLE. SUGGESTED TO MOVE CURSOR BACK AND FORTH TO BETTER APPRECIATE LIGHT FLASH EVENT.

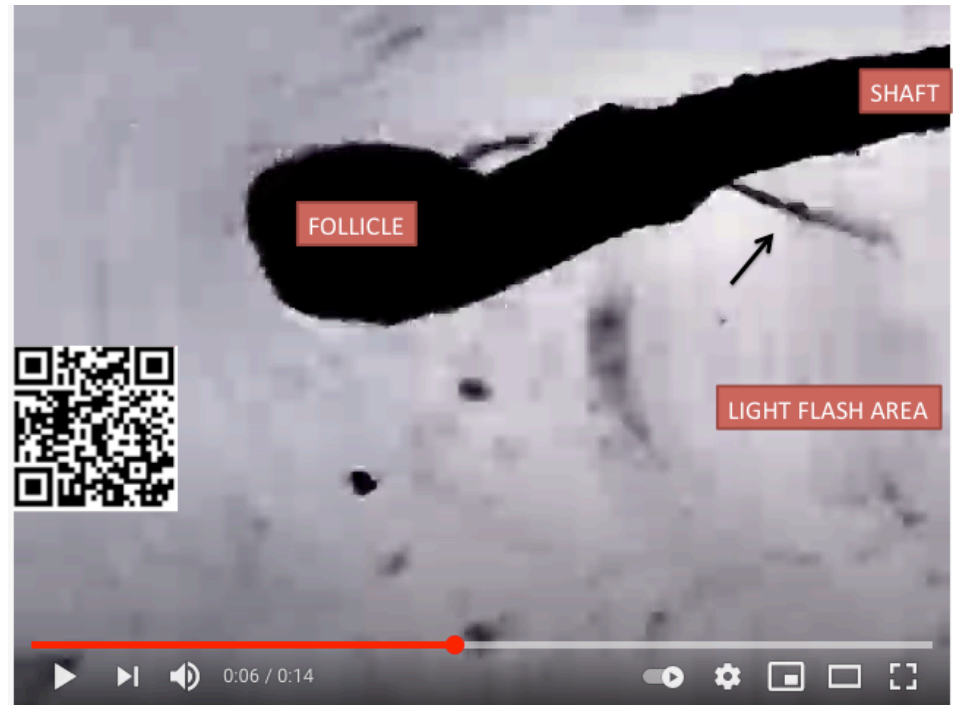

Figure 2 Samewhisker seen in Figure 1. Video frame 0.06 showing: Light Flash. Black Arrow:Pointing at mechanically displaced bulb attached filament by light flash. Fordetails link to: $\mathrm{h}$ ttps://www.youtube.com/watch?v=EiYKpN7-PpY Or Scan QR Code in left side of image.

Note: The light flash seemed to stop a temporary electromagnetic disturbance induced event.

\section{METHODOLOGY}

Some of the images and findings herein presented have been previously published; and others are from my files. References are attached to Figures and Exhbits. 


\section{FINDINGS}

When taken in context, the images (Figures 1,2 above and Exhibits + Videos below) support a curious observation that not only involves rodent and humans bioelectromagetism expressed as light; but also displacing matter.

\section{EXHIBIT 1} Rodent vibrissa whiskers spontaneously discharging light energy and skewedness of Right
sided BMFs

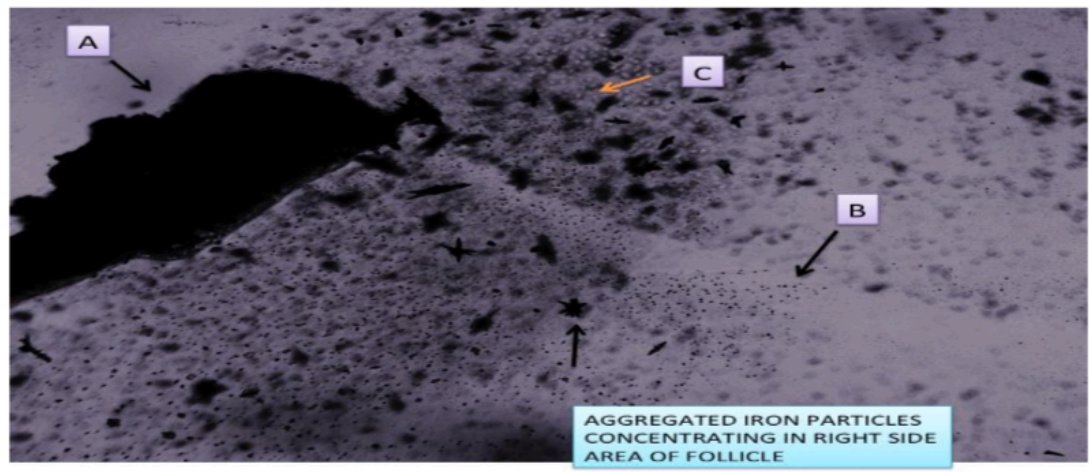

Figure 1: Unpublished image, Example of undisturbed rodent whisker in SDW PBS Fe 2K stored in the dark. A) Follicle B)

Bioelectromagnetic field expressed in the form of light energy. C) Ferrocyanide with Iron crystals partially surrounding follicle. Notice the presence of one sided magnetic activity. Image reproduced from:

Embi AA, Jacobson JI, Sahoo K, Scherlag BJ (2015) Demonstration of Electromagnetic Energy Emanating from Isolated Rodent Whiskers and the Response to Intermittent Vibrations. Journal of Nature and Science, 1(3): e52.

Image Reproduced from: Link: https://pdfs.semanticscholar.org/10f2/56e687b b8e09aa8f142e49deed3482fefa29.pdf?_ga=2.46739367.1009702324.1626650270 $-282528468.1544888008$

\section{EXHIBIT 2}

\section{RODENT WHISKER SHOWING LIGHT DISPLACING MATTER POST PROVOCATIVE MECHANICAL VIBRATION}




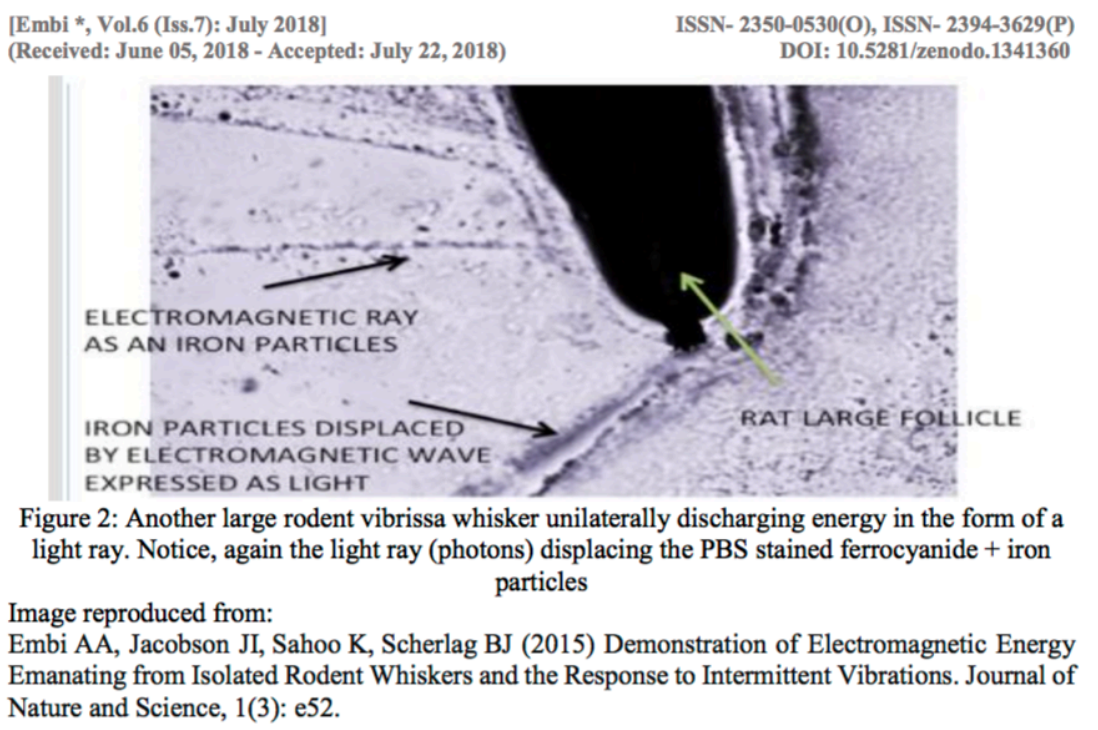

\section{LINK:}

https://pdfs.semanticscholar.org/10f2/56e687bb8e09aa8f142e49deed3482fefa2 9.pdf?_ga=2.46739367.1009702324.1626650270-282528468.1544888008

\section{EXHIBIT 3}

HUMAN HAIR FOLLICLE EMITTING BIOELECTROMAGNETISM AS LIGHT RAY ALSO DISPLACING MATTER

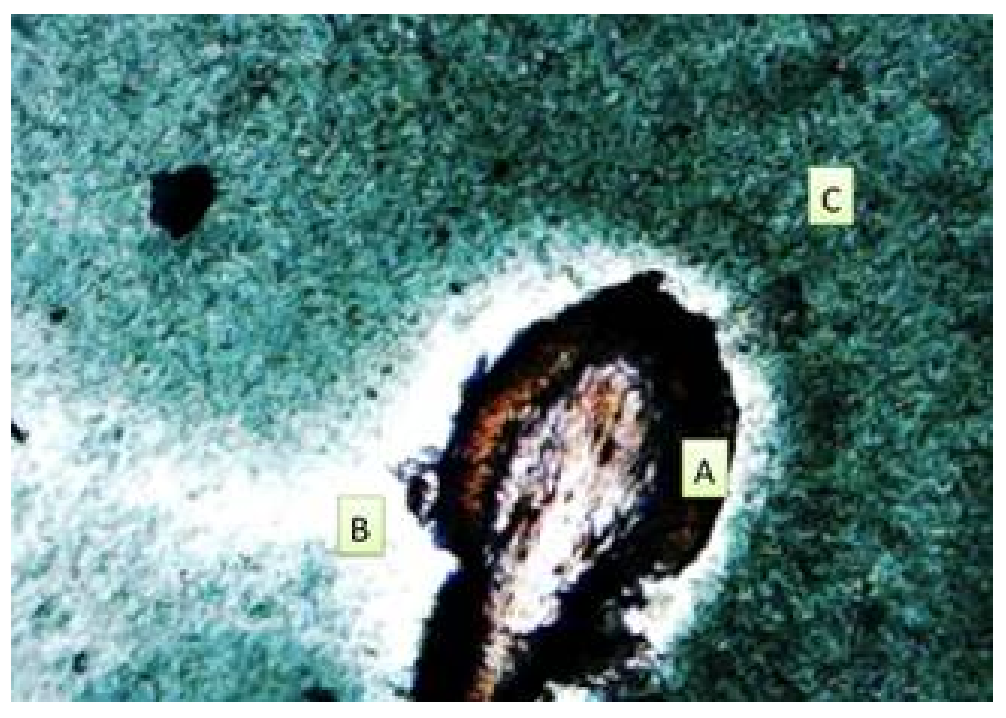

Human Hair in SDW immersed in Prussian Blue Stain showing

$\mathrm{A}=$ Follicle. $\mathrm{B}=$ Light ray blocking particles from forward motion. $\mathrm{C}=$ Potassium Ferrocyanice crystals plus very fine iron particles. 
https://www.youtube.com/watch?v=5grJrrMd77k

link to video showing particles circulating around follicle andlight stopping particles. Or Scan QR Code below

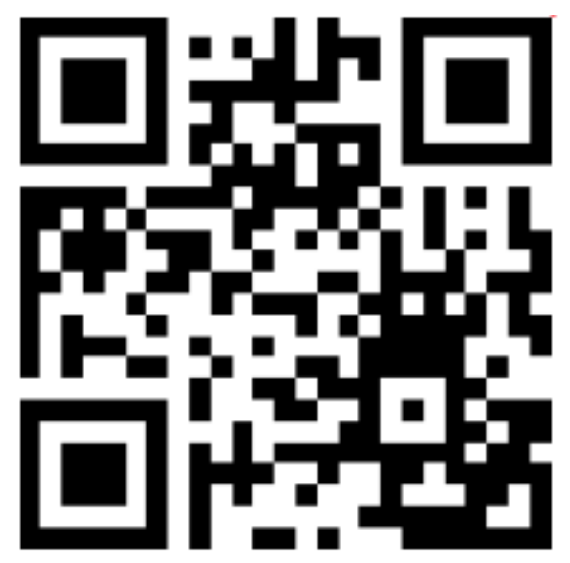

Reference: Embi AA, Jacobson JI, Sahoo K, Scherlag BJ (2015) Demonstration of Inherent Electromagnetic Energy Emanating from Isolated Human Hairs. Journal of Nature and Science, 1(3):e55.

\section{EXHIBIT 4}

$\mid$
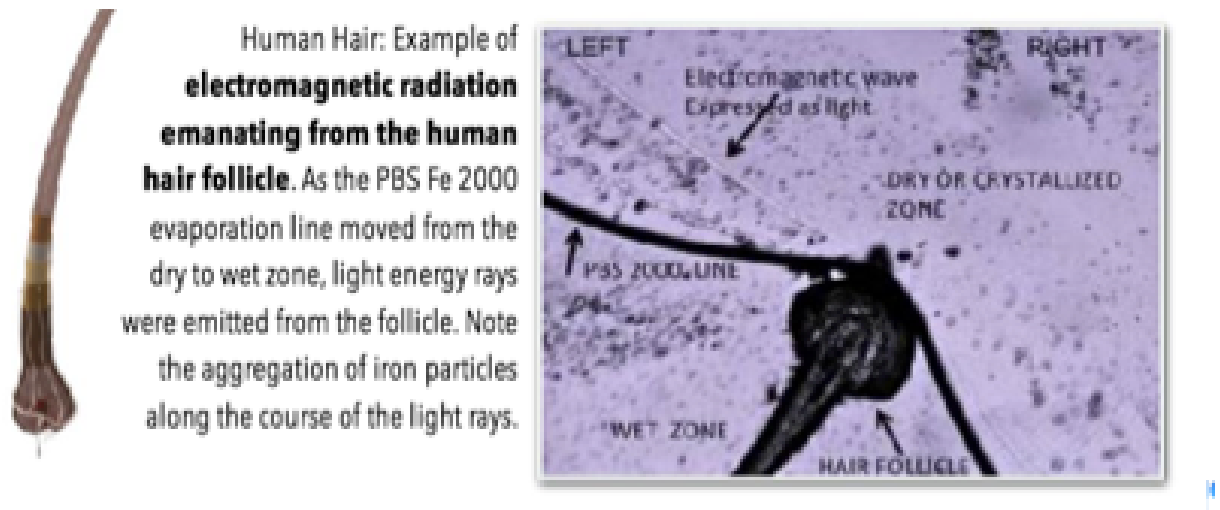

https://youtu.be/nm0FtOWEu94 ণ

link to video showing light rays emitted by human hair follicle. ๆ Link to article: http://www.jnsci.org/files/html/e55.htm

Reference: Embi AA, Jacobson JI, Sahoo K, Scherlag BJ (2015) Demonstration of Inherent Electromagnetic Energy Emanating from Isolated Human Hairs. Journal of Nature and Science, 1(3): e55. 


\section{EXHIBIT 5}

\section{ADDITIONAL EXAMPLE OF HAIR FOLLICLE BIOELECTROMAGNETISM EMIT- TING LIGHT RAYS AND DISPLACING MATTER}

\section{Shaft expressing BMFs as Light Energy Displacing Iron Particles}

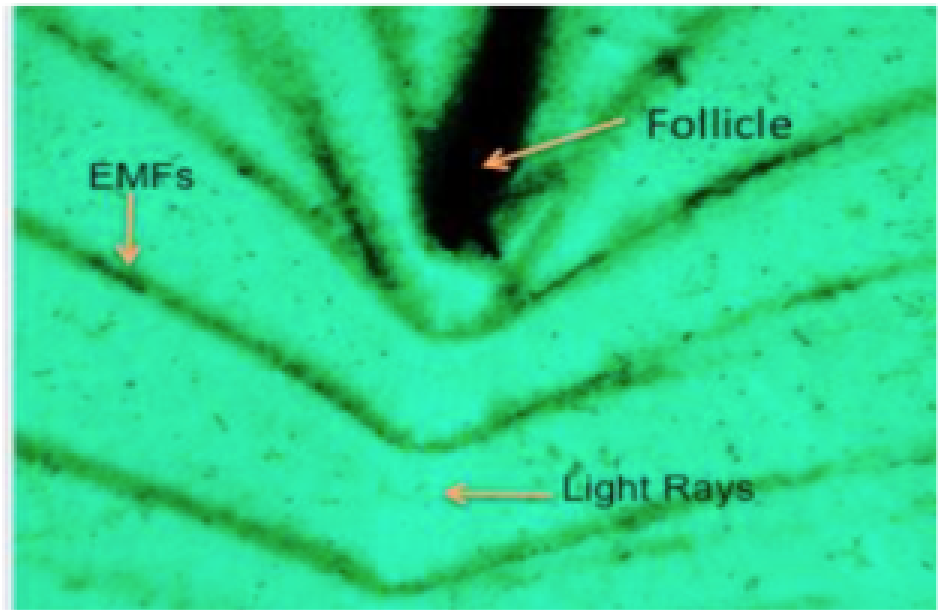

Figure 5: This image shows a human hair follicle in SDW PBS Fe2 2K The darker lines are Ferrocyanide crystals representing BMFs.

This figure also shows the power of a light ray (photons) displacing particles.

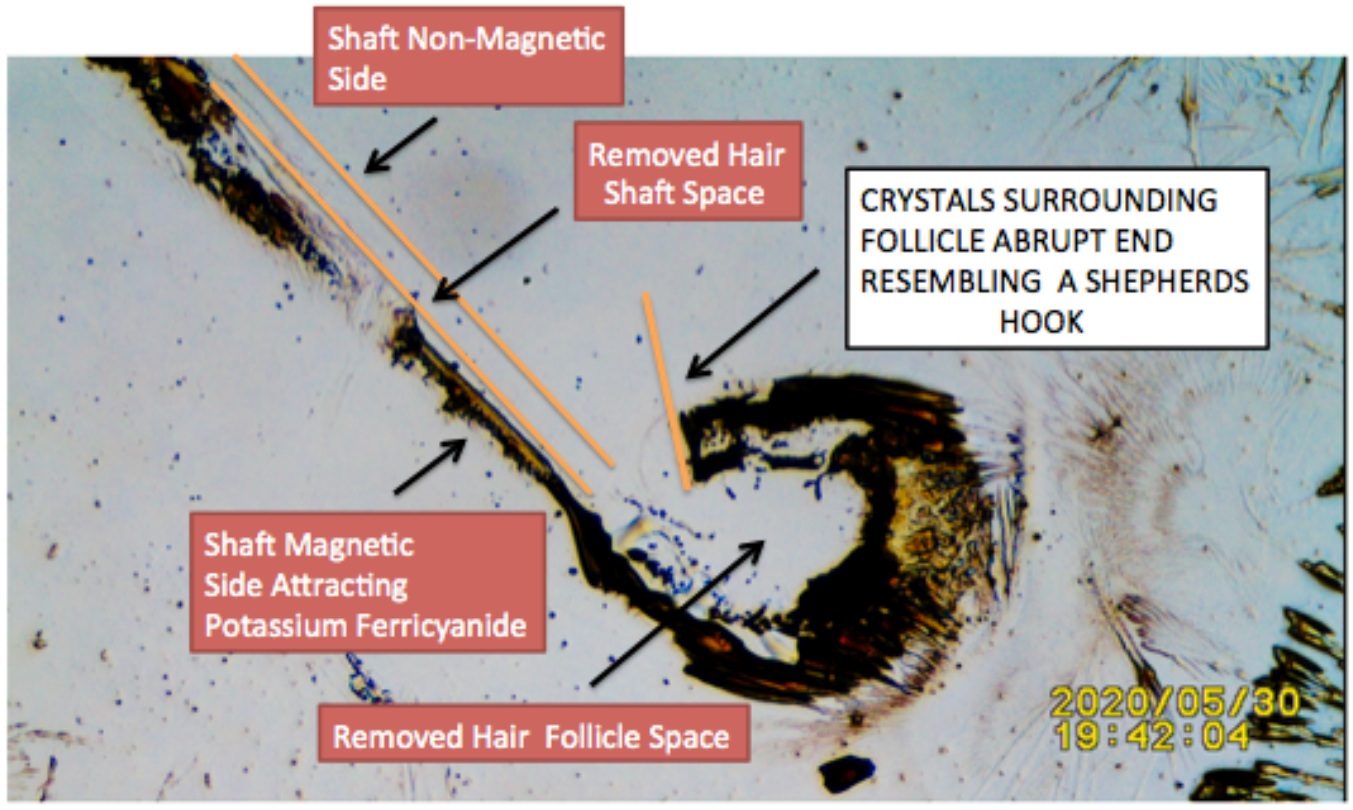


Unpublished image.The Genesis of The Shepherds Hook Pattern and The Unilateral Biomagnetism of the Human Hair Shaft. Plucked scalp hair mounted on a glass slide and covered by drops of Potassium Ferricyanide $\left(\mathrm{KFe}_{3}\right) . \mathrm{KFe}_{3}$ has been proven to "fully absorb" electromagnetic radiation. After evaporation, notice the unilateral presence of biomagnetism of the hair shaft expressed by the triggering $\mathrm{KFe}_{3}$ crystals. Also, the presence of crystals due to biomagnetism surrounding the hair follicle.

Technique explained in article below: Cite This Article: Abraham A. Embi Bs. (2018). "THE SHEPHERDS HOOK PHENOMENON PATTERN OF HAIR ROOTS A DEMONSTRATION OF COMPARATIVE BIOLECTROMAGNETISM BETWEEN HUMAN HAIRS AND MOUSE WHISKERS BY MEANS OF THE PHOTOELECTRIC EFFECT." International Journal of Research - Granthaalayah, 6(7), 317-326. https://doi.org/1 0.29121/granthaalayah.v6.i7.2018.1312.

\section{DISCUSSION/SUMMARY}

Qualitative In Vitro examples are presented showing human and rodent hair follicles emitting light. The light is shown as a flash (Figure 2), which was induced by applying finger pressure to the preparation. This could be classified as a piezoelectric effect, which is the ability of certain materials to generate an electric charge in response to applied mechanical stress. Other images and videos are labeled Exhibits, since they are previously published images by this author. References to the appropriate paper are shown.

There is a common denominator to the phenomena of light emission from living tissue, which is theorized to be triggered by the presence of external pressure during the experiments, whether from applied finger pressure or from the increased environmental pressure when tissue is "sandwiched" (SDW) between two equal glass slides.

The above findings seem to point that light originates during turmoil, and its discharge brings equilibrium as seen in Figure 2 (video). An analogy is a lightening flash during a storm, it equilibrates the local environment...until another chaotic event triggers another discharge.... and another.... until calm is restored....

\section{Hair Shaft Property of One-Sided Magnetic Fields}

As displayed in Fig.3 above, the hair shaft is shown to have one-sided electromagnetism. Demonstrated by Potassium Ferricyanide crystals formed by incoming electromagnetic radiation.

\section{Relevant Historical Note}

In a seminal paper describing the origin of magnetic fields in the human body Cohen et al. (1980) by using sophisticated equipment stated: "Most of the field over the head is produced by electrical sources associated with the hair follicles of the scalp; this field is produced only as a response to touching or pressing the scalp in regions where the hair is dense". Recently, an optical microscopy method was developed in 2015 and published a year later Benjamin et al. (2016) that also detects bioelectromagetic fields from hair follicles. That microscopy method was the 
one used to detect bioelectromagnetic emissions in the form of light when applying pressure to follicles; and is herein presented as shown in Figures 1 and 2 above.

\section{The Chest Thump Mechano-Electrical Transduction}

Https://Www.Nejm.Org/Doi/Full/10.1056/Nejm197011262832213 (2021) Additional Curious/Relevant Information Supporting Applied Pressure Converted into Electrical Energy (Transduction)

The Chest Thump and Heart Arrhythmias

New England Journal of Medicine- 1970 Editorial-

Conversion of Mechanical Input into Electrical Impulse

Cardiologic jargon terminology now includes reference to various forms of version ranging from electroversion to cardioversion and now thump-version. This latest measure dispenses with gadgets and uses immediately available mechanical energy to terminate life-threatening arrhythmia. Effectiveness of the maneuver is due to conversion of the mechanical input into an appropriate electrical pulse. Mechanoelectrical transduction plays an integral part in biologic homeostasis. Muscle-stretch spindles, the vestibular organ and baroreceptors in the great vessels depend on this mechanism to form complex feedback loops for sustaining regulation.

\section{REFERENCES}

Benjamin, J., Scherlag, K., Sahoo, A. A., \& Embi, A. (2016). Novel And Simplified Method For Imaging The Electromagnetic Energy In Plant And Animal Tissues. Journal of Nanoscience And Nanoengineering, 2(1), 6-9.

Cohen, D., Palti, Y., Bn, C., \& Sj, S. (1980). Magnetic Fields Produced By Steady Currents In The Body. Proc. Natl. Acad. Sci, 77(3), 1447-1451.

$\begin{array}{ccc}\text { (2021). Retrieved } & \text { from } & \text { Https://Www.Nejm.Org/Doi/Full/10.1056/ }\end{array}$ 